\title{
Why have GPwSIs in respiratory medicine?
}

\section{Dermot Ryan}

\section{Dermot Ryan \\ General Practitioner \\ Correspondence to: \\ Dr Dermot Ryan \\ Woodbrook Medical \\ Centre \\ 28 Bridge Street \\ Loughbourough \\ Leics LE11 1NH}

Tel +44 (0)1509 239166

Fax +44 (0)1509 239649

Email:

ryan.dermot3@virgin.net

Date submitted: $11 / 04 / 03$

Date Accepted: 01/05/03

Prim Care Resp J 2003; 12(2):36
I $\mathrm{n}$ terms of respiratory disease, the outcome parameters in the UK are almost the worst in Europe. ${ }^{1}$ Advances in respiratory care has resulted in an ability to treat many more conditions, however, our UK hospitals are overstretched. ${ }^{2}$ There is one respiratory specialist per 110,000 population in the UK compared to 1:60,000 in Europe, and without additional resource allocation, these figures are likely to become worse. ${ }^{3}$

In order to treat the burgeoning numbers of patients with chronic respiratory disease it would seem appropriate to look at a new way of addressing the issues. General Practitioners with a Special Clinical Interest (GPwSI's) are one of the possible solutions (see paper by Gruffydd-Jones et al on pp38-41) and the Government has promised at least 1,000 GPwSIs in post by $2004 .^{4}$

Many GPs made a career decision not to become hospital based specialists but whether by accident or design have acquired specialist knowledge and are willing and able to provide an enhanced service to patients in the primary care environment.

In my opinion, the GPwSI would not be a glorified clinical assistant, working under consultant supervision, but an independent practitioner, most likely employed by the Primary Care Organisation (PCO). The GPwSI in respiratory medicine would have two main roles, operational and strategic.

The operational role could be to provide an expert opinion on a patient in whom there was a difficult diagnostic or management problem. Once assessed, and a management plan agreed, the patient would be discharged back to their own primary care team. The GPwSI would also set up and provide, along with his/her dedicated team, a spirometry service at PCO level. This service might include provision of training in spirometry for members of the primary care team.

The second role, in a strategic capacity, is the area which might be more contentious but for which there is a clear need.

New services need to be developed including allergy assessment of respiratory disorders and screening of smokers for COPD. There is also a pressing need for community pulmonary rehabilitation. Studies demonstrate the feasibility but provision is currently not forthcoming. 5
One of the commonest reasons for acute hospital admission is respiratory disorder, accounting for nearly $2.5 \mathrm{million}$ bed/days per annum in the United Kingdom (UK). Provision of a respiratory care at home team could prevent many admissions and facilitate early discharge.

Part of the strategic role would also be to increase awareness of respiratory disease and its accompanying morbidity within the local primary care community; to set agreed local standards of what level of service a patient should expect ${ }^{6}$ and to provide training and educational initiatives in order to achieve these objectives.

Who will provide the service? Currently there are a number of GPs who could be appointed to such a post by virtue of their experience. In the future, some form of formal accreditation will need to be undertaken and the GPIAG is developing a core curriculum. ${ }^{7,8}$

The challenge exists for those of us working in primary care respiratory medicine. The Government has ignored the plight of the patient with chronic respiratory disorders and the properly resourced GPwSI, working at PCT level, is an opportunity to make a significant difference to the lives of many of our patients.

\section{References}

1. The Burden of Lung Disease. http://www.britthoracic.org.uk/pdf/BTSpages.pdf

2. Partridge $M$. The profile of respiratory conditions: why government action is necessary. Thorax 2001;56:744-5.

3. BTS Workforce report. http://www.britthoracic.org.uk/bts_protected/resource/Manpower\%20 Report.pdf British Thoracic Society 2002.

4.Department of Health. The NHS Plan: A plan for investment, a plan for reform. The Stationery Office. London 2000

5.Jones R, Copper S, Riley O, and Dobbs F. A pilot study of pulmonary rehabilitation in primary care. British Journal of General Practice 2002;52:567-8. 6. The Respiratory Alliance. Bridging the Gap 2003. Commissioning and delivering high quality integrated respiratory healthcare

http://www.gpiag.org/news/bridging.php

7.Gruffydd-Jones K, Ryan D, Campbell M et al. Prim

Care Resp J 2003; 12(2) ; 38-41

8.Department of Health 2003.

http://www.gpwsi.org/frameworks.htm 